\title{
Impact of complementary and alternative medicines on antiepileptic medication adherence among epilepsy patients
}

\author{
Muhammad Junaid Farrukh ${ }^{1,2}$, Mohd Makmor-Bakry ${ }^{1 *}$, Ernieda Hatah ${ }^{1}$ and Tan Hui $\operatorname{Jan}^{3}$
}

\begin{abstract}
Background: The aim of this study was to assess the knowledge, attitude, and practice of complementary and alternative medicine (CAM) and its impact on antiepileptic drug (AED) adherence among patients with epilepsy.

Methods: A cross-sectional study was carried out on 100 epilepsy patients, aged 18 years or older that did not have any physical or psychiatric illness. A patient-administered questionnaire was used to assess their knowledge, attitude towards, practice, and perceived effectiveness (KAPP) of CAM. Established adherence assessment tools were used to determine patient medication adherence.

Results: The prevalence of CAM usage was found to be at $58 \%$. CAM was used more frequently by males ( $n=32$, $60.4 \%)$ than by females $(n=26,55.3 \% ; p=0.609)$. The most commonly used CAM included vitamins and minerals (36\%), ginseng (16\%), antioxidants (15\%), and acupuncture (12\%). A significant number of patients had low knowledge of (59\%) and a positive attitude (54\%) toward complementary and alternative medicine. Main reasons for using CAM were a lower price, better availability, and inadequate seizure control by AEDs. About $43 \%$ of the patients who used CAM informed their doctor. Prevalence of non-adherence to AED therapy was found to be 68\%. A significant association was found between non-adherence and CAM usage $(p<0.01)$.

Conclusion: A high prevalence of CAM usage and non-adherence to AEDs among epilepsy patients was identified. CAM usage was associated with a non-adherence to AED therapy. This study highlights the need to explore CAM usage with patients before making clinical decisions to achieve the best outcomes from AED therapy.
\end{abstract}

Keywords: Medication adherence, AED, Epilepsy, Complementary and alternative medicine, Supplements

\section{Background}

Epilepsy is a chronic disease of the brain that can affect individuals at any age. Nearly 50 million people worldwide have epilepsy, making it one of the most common neurological disorders [1]. Most seizures can be controlled by medications called antiepileptic drugs (AEDs) [2]. Complementary and alternative medicine (CAM) is used by epileptic patients as an alternative treatment option however the

\footnotetext{
* Correspondence: mohdclinpharm@ukm.edu.my

${ }^{1}$ Faculty of Pharmacy, Universiti Kebangsaan Malaysia, Jalan Raja Muda Abdul Aziz, 50300 Kuala Lumpur, Malaysia

Full list of author information is available at the end of the article
}

effectiveness of some of them has not been established using scientific methods [3]. Globally, the percentage of CAM usage among patients with epilepsy was reported between 7.3 and $73.3 \%$ [3]. The most common CAM remedies used in the treatment of epilepsy include mind-body therapies, such as reiki and yoga; biologic-based therapies, such as herbal remedies, dietary supplements, and homeopathy; and manipulative-based therapies, such as chiropractic [4]. The type of CAM used may vary due to differences in cultural norms and healthcare settings.

In Malaysia, CAM use is prevalent among $71.2 \%$ of the general public [5]. There are several issues with CAM

C C The Author(s). 2021 Open Access This article is licensed under a Creative Commons Attribution 4.0 International License, which permits use, sharing, adaptation, distribution and reproduction in any medium or format, as long as you give appropriate credit to the original author(s) and the source, provide a link to the Creative Commons licence, and indicate if changes were made. The images or other third party material in this article are included in the article's Creative Commons licence, unless indicated otherwise in a credit line to the material. If material is not included in the article's Creative Commons licence and your intended use is not permitted by statutory regulation or exceeds the permitted use, you will need to obtain permission directly from the copyright holder. To view a copy of this licence, visit http://creativecommons.org/licenses/by/4.0/ The Creative Commons Public Domain Dedication waiver (http://creativecommons.org/publicdomain/zero/1.0/) applies to the data made available in this article, unless otherwise stated in a credit line to the data. 
use. The Malaysia Drug Control Authority (DCA) is responsible for protecting public health in ensuring the safety and efficacy of pharmaceutical and biological products. However, the safety and effectiveness of CAM are not fully regulated by the DCA [6]. CAM may cause a drug-drug interaction which may increase the risk of seizures through several mechanisms, such as intrinsic proconvulsant properties, contamination by heavy metals, effects on the cytochrome P450 enzymes and Pglycoproteins and altering antiepileptic drug (AED) disposition. Such interactions may be difficult to predict, since the quality and quantity of active ingredients are often unknown. According to a study, $50 \%$ of the patients using a CAM-based medicine had an increase in their seizures [7]. Most patients are reluctant to inform their physicians about taking a CAM based medicine as they do not consider such alternative medicines as drugs [8].

In a systematic review, the worldwide AED nonadherence rate among patients with epilepsy was reported to be between 25 and 66\% [3]. In Malaysia, the prevalence of poor adherence to AEDs has been reported as $64.1 \%$ of all epileptic patients [9]. Nonadherence to medication is a serious issue in patients with epilepsy. The belief that epilepsy has a spiritual or psychological cause contributes to inadequate AED therapy and a higher dependence on CAM [10]. Although several studies have reported the reasons for CAM usage among epilepsy patients, the global data on evidence of AED non-adherence and its association with CAM usage is scarce. Therefore, the objective of this study was to determine the prevalence of CAM usage, to evaluate the knowledge, attitude towards, and practice of CAM and its impact on AED adherence among patients with epilepsy.

\section{Methods}

\section{Study design}

We conducted a cross-sectional study on 100 patients diagnosed with epilepsy to evaluate the knowledge, attitude towards, practice, and perceived effectiveness of CAM. The patients were recruited from the neurology clinic at the Hospital University Kebangsaan Malaysia.

\section{Sample size}

Sample size was calculated based on descriptive survey using Raosoft Calculator (Raosoft Inc. 2004). The margin of error and confidence interval were set at 5 and $95 \%$, respectively. Response distribution was set at $50 \%$ to get the higher sample size. Population size was estimated at 150 for epilepsy patient within the duration of study as the clinic was run 2 days a week. Thus, a total of 109 patients was estimated as the sample size.

\section{Study setting}

The patients were recruited from the neurology clinic at the Hospital Universiti Kebangsaan Malaysia from March 2017 to November 2018.

\section{Sampling method}

Data was collected using simple random sampling. First the appointment list of patients was obtained from the clinic appointment record and then patients were randomly selected using a random number generator. Random Number Generator ${ }^{\circ}$, Android App developed by Ux Apps will be used (Random Number Generator 2016). Patients were recruited based on the following criteria.

\section{Inclusion criteria}

Epilepsy patients who were 18 years or older and had been on an AED for at least 6 months, without any documented physical or psychiatric illness such as schizophrenia and major depression were included.

\section{Assessment tools}

The questionnaires comprised of seven main sections which were adapted from previous studies [11, 12]. Section A captured basic socio-demographic data, including age, sex, religion, marital status, level of education, monthly income, number of comorbidities, and number of medications. Section B consisted of knowledge about CAM (4 questions), with a correct answer scored as 1 (maximum score $=4$ ). Section $C$ covered the types of CAM and their perceived effectiveness of CAM. Section D and Section E consisted of attitude (8 questions) and the practice of CAM (8 questions), respectively. It was modified and translated into the Malay language using the forward-backward translation method. Content validity was assessed by five experts (physician, academics, and pharmacists). A pilot study was first carried out on 30 epileptic patients to ensure the reliability of the questionnaire formulated. The internal consistency was calculated using Cronbach's alpha coefficient, which was 0.7 for knowledge, 0.73 for attitude, and 0.85 for practice. Section F consisted of the Malaysian Medication Adherence Scale (MALMAS) [13] and the Medication Possession Ratio (MPR) [14] so as to assess adherence. The MPR was determined from our pharmacy information system (PIS) by calculating the number of days' supply of medication dispensed divided by the number of days between the first and last prescription refill. If any of the two tools showed nonadherence, patients were considered as non-adherent.

\section{Ethical considerations}

Ethical approval was obtained from the UKMC ethical committee, reference no. UKM PPI/111/8/JEP-2017-138. 
Written informed consent was obtained from all patients before participation in the study.

\section{Data collection}

The patients were identified for participation in the study by a physician. Patients were informed about the purpose of this research. When appropriate, nurses also assisted patients filling in the questionnaires. CONSORT flow diagram showing participants recruitment process is presented as Fig. 1.

\section{Statistical analyses}

Statistical analyses were performed using the IBM SPSS Statistics Version 23. To analyze categorical variables frequencies and percentages were used. For continuous variables describing the study population, descriptive statistics, including the mean and standard deviation (SD), were used. For the knowledge questions asked, each question had two possible responses ('yes' and 'no'). A scoring method was used for analysis. A correct answer was given a score of 1 , while an incorrect answer was scored 0 . For the attitude and practice questions, a Likert rating scale of five points was used. There were seven attitude questions, each question was given a score as follows: Strongly agree $=5$, Agree $=4$, Not sure $=3$, Disagree $=2$ and Strongly disagree $=1$. Question 8 was given a reverse score. For the six practice questions, each question was given a score as follows: Strongly agree $=1$, Agree $=2$, Not sure $=3$, Disagree $=4$ and Strongly disagree $=5$. Questions 3 and 5 were given a reverse score. The mean of the total scores for knowledge and practice was used to determine the midpoint of 'good knowledge', 'positive attitude' and 'good practice' [15]. Univariate analysis to study the relationship between the variables and CAM usage was done using Chi-square test and Independent t-test where necessary. Association between adherence and CAM usage was analysed using Chi-square test. Variables with $p<0.05$ was considered as statistically significant $p$ value.

\section{Results}

For this survey, a total of 132 patients were approached and out of them 21 patients refused to participate. The response rate of the patients was $84.09 \%$. The reasons given by the patients for not participating in this survey were time constraints $(n=8)$ and unwilling to participate $(n=13)$. In total, 47 females and 53 males between the ages of 18 and 79 years old participated in our study. The mean age was 40.18 (SD 17.9) years old. The prevalence of CAM use was found to be $58 \%$ among the studied population. CAM use was more frequent in males $(n=32,60.4 \%)$ as compared to females $(n=26,55.3 \%)$ however, this difference was not significant. The majority of patients were Malay $(n=51)$, and Chinese $(n=36)$,

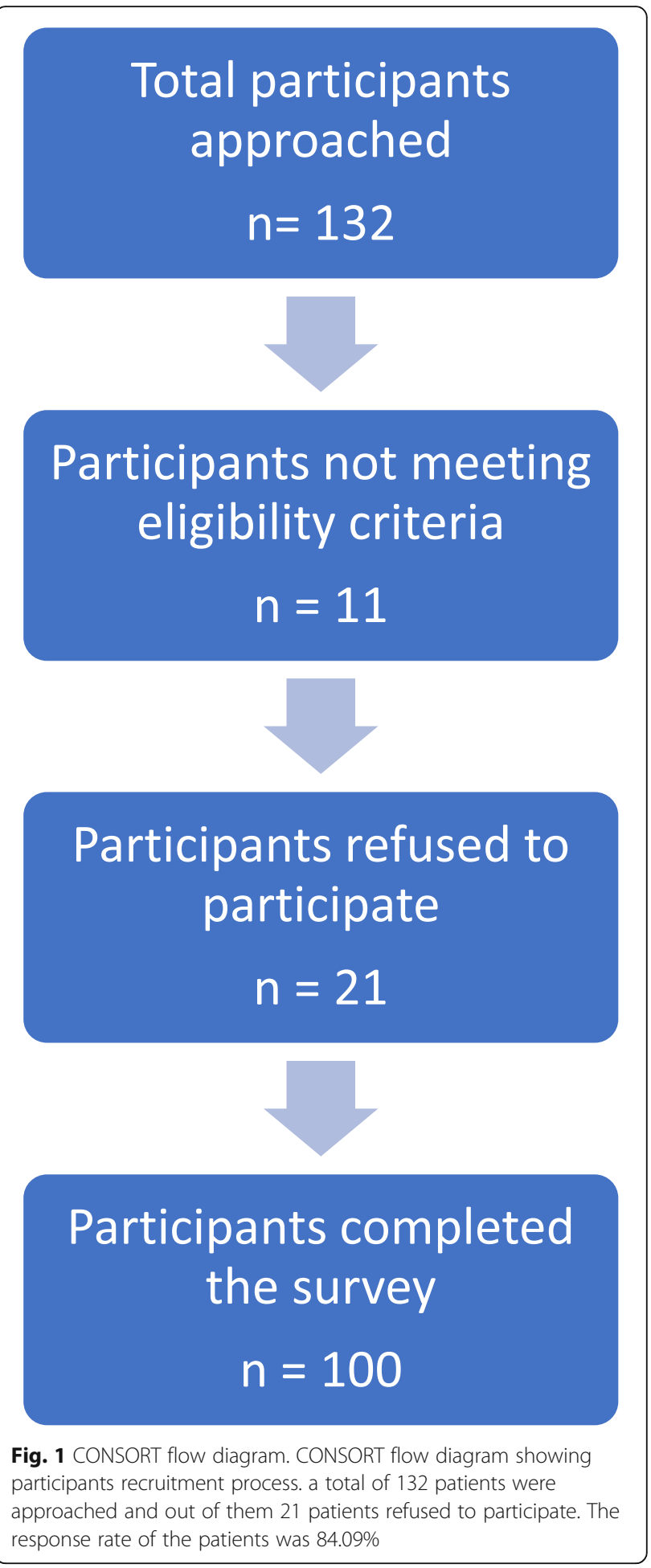

while the remaining patients were Indian $(n=13)$. Patients represented varying education levels, ranging from having had no formal education to a post-graduate qualification. The number of comorbidities varied among the patients (range between 0 to 4 ) with mean of 1.87 (SD 1.01). Seventy-nine percent of patients reported 
that they had heard of CAM. The primary source of information on CAM were friends (39\%), family (27\%), internet (19\%) and doctor (15\%). The socio-demographic characteristics of the patients and their profile of CAM use are presented in Table 1.

The most commonly used CAM included vitamins and minerals $(n=36,62 \%)$, ginseng $(n=16,27.5 \%)$, antioxidants $(n=15,25.8 \%)$ and acupuncture $(n=12$, $20.6 \%)$. The majority $(68.1 \%)$ of patients reported that CAM was effective. The main reasons for using CAM were that it was cheaper, better availability and due to inadequate seizure control by AEDs. Only $43.1 \%$ of the patients who were using CAM revealed the practice to their doctors. A significant number of patients had low knowledge and a positive attitude towards complementary and alternative medicine. The distribution and perceived effectiveness of CAM usage, as reported by the patients, is summarized in Table 2.

The average knowledge, attitude, and practice scores were determined as 2.09 (SD 1.3), 28.3 (SD 5.4) and 21.3 (SD 8.0), respectively. The majority of patients showed poor knowledge (59\%), positive attitude (54\%), and poor practices of CAM (51.7\%). A significant difference was identified in the mean attitude score between CAM users and non-users $(p=0.05)$. The attitude score showed a negative correlation with CAM practice $(r=-$ $0.404, p<0.01)$. Patients with a higher score in knowledge displayed better CAM practices $(r=0.347$, $p=0.05)$. This data is summarized in Table 3.

\section{Adherence to AED}

The prevalence of AED non-adherence was $68 \%$. There was no significant difference between adherence status and most of the sociodemographic indicators. However, it was found that patients who were married $(p=0.052)$ and had a higher level of education showed good adherence $(p<0.01)$. The mean difference in the number of comorbidities and the number of medicines was higher among non-adherent patients $(p<0.01)$.

Reasons of non-adherence reported by the patients were forgetfulness $(n=38)$, missing a dose when away from home $(n=46)$, difficulty in taking medicine $(n=45)$, problem in remembering to take medicine $(n=33)$ and stopping medicines after feeling better $(n=15)$. Patients who were adherent to AED showed good knowledge, poor attitude, and good practice towards CAM usage. Comparison of knowledge, attitude, and practice of CAM scores and adherence status are summarized in Table 4.

There was a significant relationship seen between medication non-adherence and CAM use $(p<0.01)$. This was seen to be more prevalent among patients with a lower education level. The relationship between CAM use and medication adherence is shown in Table 5.

Table 1 Socio-demographic characteristics and CAM Usage

\begin{tabular}{|c|c|c|c|c|}
\hline Item & Overall & CAM User & CAM Non-User & Statistics \\
\hline Age in years, mean (SD) & $40.18(17.9)$ & $47.19(17.6)$ & $43.05(16.0)$ & $0.232^{a}$ \\
\hline \multicolumn{5}{|l|}{ Sex, n (\%) } \\
\hline Male & $53(53)$ & $32(60.4)$ & $21(39.6)$ & \multirow[t]{2}{*}{$0.609^{b}$} \\
\hline Female & $47(47)$ & $26(55.3)$ & $21(44.7)$ & \\
\hline \multicolumn{5}{|l|}{ Race, n (\%) } \\
\hline Malay & $51(51)$ & $26(51)$ & $25(49)$ & \multirow[t]{3}{*}{$0.214^{b}$} \\
\hline Chinese & $36(36)$ & $22(61.1)$ & $14(38.9)$ & \\
\hline Indian & $13(13)$ & $10(76.9)$ & $3(23.1)$ & \\
\hline \multicolumn{5}{|l|}{ Education Level, n (\%) } \\
\hline No formal education & $2(2)$ & $0(0)$ & $2(100)$ & \multirow[t]{6}{*}{$0.08^{b}$} \\
\hline Primary school & $18(18)$ & $12(66.7)$ & $6(33.3)$ & \\
\hline Secondary school & $48(48)$ & $30(62.5)$ & $18(37.5)$ & \\
\hline Diploma & $6(6)$ & $4(66.7)$ & $2(33.3)$ & \\
\hline Undergraduate & $20(20)$ & $7(35)$ & $13(65)$ & \\
\hline Post-graduate & $6(6)$ & $5(83.3)$ & $1(16.7)$ & \\
\hline \multicolumn{5}{|l|}{ Marital Status, n (\%) } \\
\hline Single & $32(61.5)$ & $20(38.5)$ & & \multirow[t]{3}{*}{$0.751^{b}$} \\
\hline Married & $25(54.3)$ & $21(45.7)$ & & \\
\hline Divorced & $1(50)$ & $1(50)$ & & \\
\hline Number of co-morbidities, mean (SD) & $1.87(1.01)$ & $2.0(1.0)$ & $1.69(0.9)$ & $0.132^{\mathrm{a}}$ \\
\hline
\end{tabular}

$\mathrm{a}=$ Independent $\mathrm{t}$-test; $\mathrm{b}=\mathrm{Chi}$-square test 
Table 2 Distribution and perceived effectiveness of CAM usage

\begin{tabular}{|c|c|c|}
\hline Types of CAM used & $\%$ of user, $n(\%)$ & $\%$ of those perceived effective, $n(\%)$ \\
\hline \multicolumn{3}{|l|}{ Mind and Body practice $(n=47)$} \\
\hline Acupuncture & $12(20.6)$ & $6(50)$ \\
\hline Aromatherapy & $5(8.6)$ & $4(80)$ \\
\hline Cupping & $5(8.6)$ & $3(60)$ \\
\hline Massage & $12(20.6)$ & $6(50)$ \\
\hline Prayer for health & $5(8.6)$ & $4(80)$ \\
\hline Structured Exercise & $8(13.7)$ & $2(25)$ \\
\hline \multicolumn{3}{|l|}{ Natural Products $(n=79)$} \\
\hline Antioxidants & $15(25.8)$ & $11(73.3)$ \\
\hline Detoxifying diet & $2(3.4)$ & $1(50)$ \\
\hline Ginseng & $16(27.5)$ & $12(75)$ \\
\hline Spirulina & $4(6.8)$ & $4(100)$ \\
\hline Unknown Herbal & $6(10.3)$ & $4(100)$ \\
\hline Vitamins and minerals & $36(62)$ & $23(63.8)$ \\
\hline \multicolumn{3}{|l|}{ Others } \\
\hline \multicolumn{3}{|l|}{ Traditional Medicine $(n=22)$} \\
\hline Homeopathy & $3(5.17)$ & $3(100)$ \\
\hline Traditional Chinese Medicine & $8(13.7)$ & $8(100)$ \\
\hline Traditional Indian Medicine & $4(6.89)$ & $2(50)$ \\
\hline Traditional Malay Medicine & $7(12)$ & $5(71.4)$ \\
\hline
\end{tabular}

\section{Discussion}

Epilepsy is a stigmatizing neurological disorder that often results in significant physical, psychological, and financial burden on both individuals and families [16]. Problems associated with epilepsy are further aggravated when patients neglect to take their antiepileptic drug (AED) therapy and begin depending on other treatment options [17]. The goal of this study was to assess the knowledge, attitude, and practice of complementary and alternative medicine (CAM) and its impact on antiepileptic drug (AED) adherence among patients with epilepsy.

The findings revealed a high prevalence of CAM usage among patients with epilepsy. The prevalence of CAM use among epilepsy patients reported in this study is higher than an earlier study reported in Malaysia [18]. This could be due to having a larger sample size and the comprehensive, detailed categories of CAM used by our study. The global prevalence of CAM use reported in previous studies was between 7.5 and $73.3 \%$. A systematic review on the CAM usage among epilepsy patients reported that CAM is more widely used in developed countries as compared to developing countries. However, the definition of CAM and types of CAM may also vary among developed and developing countries [3]. Although Malaysia is a developing country, the higher prevalence of CAM usage may be due to the multi-racial culture in Malaysia where the people have various treatment choices ranging from culturally specific traditional medicines to modern CAM [3]. Malaysia's healthcare system is divided into two highly developed sectors, a government-led and funded public sector, and a booming private. The public sector caters to about $65 \%$ of the population [19]. Furthermore, the cost of epilepsy medications is very high especially the newer agents as they are imported from other countries and are not easily accessible. Patients with low socioeconomic background might not be able to afford such high cost of new medicine and need to continue with the generic medicine available in the government or public health clinics. A study done on the cost-effectiveness of AEDs for the management of epilepsy in Malaysia reported that they newer agents were considered non-cost-effective in controlling seizures [20]. In Malaysia most of the insurance policies do not cover epilepsy, so it is very difficult for an epilepsy patient who needs AEDs to claim from insurance, so they tend to rely on CAM [21].

The most popular CAM reported in this study were vitamins and minerals, ginseng, antioxidants, and acupuncture. The type of CAM usage varied between different age-groups. Acupuncture, traditional Chinese and Malay medicines were mostly used by elderly patients. The younger population was seen to be widely using vitamins and supplements due to marketing and 
Table 3 Predictivity of attitude statements on CAM usage

\begin{tabular}{|c|c|c|c|c|c|}
\hline Characteristics & CAM User & $\begin{array}{l}\text { CAM } \\
\text { Non-User }\end{array}$ & $p$-value & OR & $95 \% \mathrm{Cl}$ \\
\hline \multicolumn{6}{|c|}{ CAM provides quick and additional relief } \\
\hline Yes & $53(67.1)$ & $26(32.9)$ & $<0.001$ & 6.523 & $2.15-19.17$ \\
\hline No & $5(23.8)$ & $16(76.2)$ & & & \\
\hline \multicolumn{6}{|c|}{ CAM is cheaper compared to modern medicine } \\
\hline Yes & $54(62.1)$ & $33(37.9)$ & 0.03 & 3.6 & $1.05-12.09$ \\
\hline No & $4(30.8)$ & $9(69.2)$ & & & \\
\hline \multicolumn{6}{|c|}{ CAM provides a permanent cure } \\
\hline Yes & $50(72.5)$ & $19(27.5)$ & $<0.001$ & 7.5 & $2.8-19$ \\
\hline No & $8(25.8)$ & $23(74.2)$ & & & \\
\hline \multicolumn{6}{|c|}{ People use CAM because it is easily available } \\
\hline Yes & $50(72.5)$ & $19(27.5)$ & $<0.001$ & 7.5 & $2.8-19$ \\
\hline No & $8(25.8)$ & $23(74.2)$ & & & \\
\hline \multicolumn{6}{|c|}{ CAM providers give good information about CAM } \\
\hline Yes & $48(67.6)$ & $23(32.4)$ & 0.002 & 3.9 & $1.5-9.8$ \\
\hline No & $10(34.5)$ & $19(65.5)$ & & & \\
\hline \multicolumn{6}{|c|}{ CAM promotes self-healing } \\
\hline Yes & $51(69.9)$ & $22(30.1)$ & $<0.001$ & 6.62 & $2.4-17.9$ \\
\hline No & $7(25.9)$ & $20(74.1)$ & & & \\
\hline \multicolumn{6}{|c|}{ People use CAM due to fearing discomfort from allopathic medicines } \\
\hline Yes & $42(76.4)$ & $13(23.6)$ & $<0.001$ & 5.8 & $2.4-13.9$ \\
\hline No & $16(35.6)$ & $29(64.4)$ & & & \\
\hline \multicolumn{6}{|c|}{ CAM should be used only in minor illness } \\
\hline Yes & $12(33.3)$ & $24(66.7)$ & $<0.001$ & 0.196 & $0.08-0.47$ \\
\hline No & 46 (71.9) & $18(28.1)$ & & & \\
\hline
\end{tabular}

promotional strategies by companies to attract them. The higher use of CAM in the elderly can be justified by an increased number of chronic diseases, most of which can only be controlled and not cured with current conventional treatment options [22]. The types of CAM used in this study were comparable to previous studies, other than some variation that was caused by differences in cultural and traditional norms. For example, in Western countries, the use of vitamins, herbs, and yoga was more prevalent [23-25]. Prayer for health and amulets was common in Middle-eastern countries [26]. In India, Ayurveda was more frequently practiced [27-29] whereas, in Taiwan, traditional Chinese medicines were seen to be used more frequently [30].
Table 5 Relationship between CAM usage and medication adherence

\begin{tabular}{llll}
\hline Item & Adherent & Non-Adherent & $\boldsymbol{p}$-value \\
\hline CAM user & 8 & 50 & $<0.01^{\mathrm{a}}$ \\
CAM Non-user & 24 & 18 & \\
\hline $\mathrm{a}=$ Chi-square test & &
\end{tabular}

The majority of patients showed poor knowledge and a positive attitude towards CAM usage. The majority of CAM users showed poor practices of CAM. Malay patients and patients with a higher level of education had good knowledge of CAM. Attitude scores showed a negative correlation with the knowledge score, level of education and CAM practice. Patients that displayed high knowledge showed good CAM practices. Similar results were reported in a study carried out in Malaysia among the general population [31]. People who were using CAM showed a stronger belief in it, with a more positive attitude towards CAM than those who were not using it. This may indicate that education is needed to explain both the pros and cons of using CAM. Moreover, if patients are well-educated, they will have a better understanding of the etiology of epilepsy, the importance of AED's and the pros and cons of using CAM.

Primary reasons for using CAM included a lower price, better availability, and patients not receiving adequate seizure control using AEDs. Most CAM users had a lower level of education. This could explain their poor knowledge but positive attitude scores towards CAM. Based on these results it seems that patients can get CAM easily from pharmacies and retail stores, even though it is not clear how effective CAM products are on specific illnesses such as epilepsy. Pharmacists themselves felt they needed to attain more knowledge about CAM [5]. A study done in Singapore found that $81 \%$ of pharmacists thought that they did not possess sufficient skills and knowledge to counsel patients on herbal medicine and $90.5 \%$ felt that their education curriculum should include more content on CAM [32].

Another important finding from this study was that CAM users did not disclose the usage of CAM to their doctors. A similar finding has been reported in studies done in Malaysia, Singapore, Australia in which respondents did not reveal the use of CAM and any unwanted side effects from CAM use to their healthcare providers [33-35]. This highlights the need for community

Table 4 Comparison of Knowledge, Attitude, and Practice of CAM scores and adherence status

\begin{tabular}{lllll}
\hline Item (Range of score) & Descriptive, Mean (SD) & Adherent & Non-Adherence & $p$-values \\
\hline Knowledge (0-4) & $2.09(1.3)$ & $2.8(1.2)$ & $1.73(1.2)$ & $<0.01^{\mathrm{a}}$ \\
Attitude (5-40) & $28.3(5.4)$ & $23.7(4.7)$ & $30.4(4.4)$ & $<0.01^{\mathrm{a}}$ \\
Practice (5-40) & $21.3(8.0)$ & $32(4.2)$ & $19.6(7.1)$ & $<0.01^{\mathrm{a}}$ \\
\hline
\end{tabular}


pharmacists and doctors to ask patients regarding CAM use and appropriately counsel patients on both CAM use and misuse, as well as possible interactions with AEDs. This may help to improve therapeutic outcomes and minimize interactions with AEDs, therefore improving the patient's quality of life.

The prevalence of AED non-adherence was found to be $68 \%$. In a systematic review, the global prevalence of non-adherence among epileptic patients ranged between 25 and 66\% [3]. Moreover, the overall adherence level in western countries was seen to be higher than in Asian counties. This indicates that people residing in developing countries prefer traditional medicines to modern allopathic medicines due to cultural norms. In a previous study done in Malaysia, poor adherence to AEDs was documented as being $64.1 \%$ of patients with epilepsy [9]. Our study had a slightly higher poor adherence rate than this which may be due to the combination of subjective and objective assessment tools utilized compared to the previous study which only used a subjective assessment method. Using a subjective self-reporting method is known to result in over-reporting of good adherence [36].

It was found that patients who were married and had a higher level of education showed good medication adherence. Similar findings were reported in a study where un-married patients were more likely to be nonadherent than married patients [37]. According to a meta-analysis, social support is consistently associated with greater medication adherence [37]. This shows that patients who are married are more adherent towards taking medication as their partners play an important role in reminding them to take their medication and following them up.

The most common reasons for non-adherence were forgetfulness, missing dose when away from home, difficulty in taking medicine, problem in remembering to take medicine, fear of AED side effects and stopping medicines after feeling better. Similar findings were reported in other studies [16, 38-40].

CAM users were to a greater extent, non-adherent as compared to non-CAM users. The majority of CAM users reported concurrent use with allopathic medicines. Comparable results were reported previously in Honduras and Poland where most CAM users were seen to be non-adherent to AEDs [10, 41]. Use of AEDs along with CAM results in complex polypharmacy. This potentially leads to non-adherence as it could contribute to patients forgetting to take all their medicines and skipping doses.

Patients who were non-adherent to AED had poor knowledge, positive attitude and poor practice towards CAM use. This was in-line with the results reported in a study where widespread non-adherence to AEDs was attributed to inadequate education and wide usage of CAM [10]. It is imperative to educate patients about the common etiologies of epilepsy and in most cases that AEDs are an effective treatment.

\section{Limitations}

Although the current study has highlighted a number of significant findings, there are some limitations. We did not record the type of epilepsy and AEDs which the patient was taking and are, therefore, unable to relate this to the potential reasons for AED non-adherence. There were a substantial number of patients who refused to take part in the survey, or were excluded due to critical condition and not fit to be interviewed thus the sample size was relatively small. Further research is needed to generalise these results to different clinical settings and on larger sample size. Moreover, an investigation into the effects of CAM use on epilepsy control would provide insight into the potential benefit and harm of CAM.

\section{Conclusion}

A high prevalence of CAM use and non-adherence to AEDs among epilepsy patients was identified. This high rate of CAM use was seen to impact a patient's medication adherence. There is a need for patient education related to CAM use and AED therapy. The use of CAM should be explored with patients before clinical decisions are made so as to achieve the best treatment outcomes from AED therapy.

\section{Supplementary Information}

The online version contains supplementary material available at https://doi. org/10.1186/s12906-021-03224-2

Additional file 1. Data collection form.

\section{Abbreviations}

CAM: Complementary and alternative medicine; AED: Antiepileptic drug; KAPP: Knowledge, attitude, practice, and perceived effectiveness; MALM AS: Malaysian medication adherence scale; MPR: Medication possession ratio

Acknowledgments

We thank the UKMMC Neuromedical staff for helping with data collection.

Authors' contributions

MMB conceptualized the study and performed the analysis and interpretation of the data. MJF collected data and wrote the original manuscript. EH helped in creating our methodology and assisted in manuscript writing. HJT helped with data collection and reviewed the manuscript. All authors have made an intellectual contribution to the work and have approved the final version of the manuscript for submission.

Funding

Authors did not receive any funding for this project.

Availability of data and materials

The datasets generated during and/or analyzed during the current study are available from the corresponding author on reasonable request. 


\section{Ethics approval and consent to participate}

Ethical approval was obtained from the UKMC ethical committee, reference no. UKMPPI/111/8/JEP-2017-138. Written informed consent was obtained from all the participants before they participated in the study.

\section{Consent for publication}

Not applicable.

\section{Competing interests}

The author(s) declare no competing interests.

\section{Author details}

'Faculty of Pharmacy, Universiti Kebangsaan Malaysia, Jalan Raja Muda Abdul Aziz, 50300 Kuala Lumpur, Malaysia. ${ }^{2}$ Faculty of Pharmaceutical Sciences, UCSI University, Kuala Lumpur, Malaysia. ${ }^{3}$ Faculty of MedicinePusat Perubatan Universiti Kebangsaan Malaysia (PPUKM), Kuala Lumpur, Malaysia.

\section{Received: 13 September 2019 Accepted: 24 January 2021}

Published online: 04 February 2021

\section{References}

1. WHO. Epilepsy fact sheet. Geneva: WHO; 2016. http://www.who.int/ mediacentre/factsheets/fs999/en/. Accessed Jul 102019

2. Marks WJ, Garcia PA. Management of seizures and epilepsy. Am Fam Phys. 1998:57(7):1589 600, 1603, 603-4 [Pubmed:9556647].

3. Farrukh MJ, Makmor-Bakry M, Hatah E, Tan HJ. Use of complementary and alternative medicine and adherence to antiepileptic drug ther apy among epilepsy patients: a systematic review. Patient Prefer Adherence. 2018;12: 2111-21. https://doi.org/10.2147/PPA.S179031 Pubmed:30349205.

4. Rhodes PJ, Small N, Ismail H, Wright JP. The use of biomedicine, complementary and alternative medicine, and ethnomedicine for the treatment of epilepsy among people of south Asian origin in the UK. BMC Complement Altern Med. 2008;8(1):7. https://doi.org/10.1186/1472-6882-8-7 Pubmed:18366698

5. Jasamai M, Islahudin F, Samsuddin NF. Attitudes towards complementary alternative medicine among Malaysian adults. J Appl Pharm Sci. 2017;7(06) 190-3.

6. Chu MM. Traditional medicine lacks stringent regulations. Star Online. https://www.thestar.com.my/news/nation/2018/11/27/traditional-medicinelacks-stringent-regulations. Accessed Aug 16 2019; 2018.

7. Szabo CA. Patient page. Complementary/alternative medicine for epilepsy. Neurology. 2003;61(4):E7-8. https://doi.org/10.1212/wnl.61.4.e7 Pubmed: 12939458.

8. Skalli S, Zaid A, Soulaymani R. Drug interactions with herbal medicines. Ther Drug Monit. 2007;29(6):679-86. https://doi.org/10.1097/FTD. 0b013e31815c17f6 Pubmed:18043467.

9. Tan X, Makmor-Bakry M, Lau C, Tajarudin F, Raymond A. Factors affecting adherence to antiepileptic drugs therapy in Malaysia. Neurol Asia. 2015; 20(3):235-41.

10. Durón RM, Medina MT, Nicolás O, Varela FE, Ramírez F, Battle SJ, et al. Adherence and complementary and alternative medicine use among Honduran people with epilepsy. Epilepsy Behav. 2009;14(4):645-50. https:// doi.org/10.1016/j.yebeh.2009.01.022 Pubmed:19435580.

11. Chui PL, Abdullah KL, Wong LP, Taib NA. Prayer-for-health and complementary alternative medicine use among Malaysian breast cancer patients during chemotherapy. BMC Complement Altern Med. 2014;14(1): 425. https://doi.org/10.1186/1472-6882-14-425 Pubmed:25358688.

12. Patterson $\mathrm{C}$, Arthur $\mathrm{H}$. A complementary alternative medicine questionnaire for young adults. Integr Med Insights. 2009;4:1-11. https://doi.org/10.4137/ IMI.S2281 Pubmed:21614159.

13. Chung WW, Chua SS, Lai PSM, Morisky DE. The Malaysian medication adherence scale (MALMAS): concurrent validity using a clinical measure among people with type 2 diabetes in Malaysia. PLoS One. 2015;10(4): e0124275. https://doi.org/10.1371/journal.pone.0124275 Pubmed:25909363.

14. Andrade SE, Kahler KH, Frech F, Chan KA. Methods for evaluation of medication adherence and persistence using automated databases. Pharmacoepidemiol Drug Saf. 2006;15(8):565-74. https://doi.org/10.1002/ pds.1230 discussion 575 [Pubmed:16514590].

15. Dawood OT, Hassali MA, Saleem F. Factors affecting knowledge and practice of medicine use among the general public in the state of Penang,
Malaysia. J Pharm Health Serv Res. 2017;8(1):51-7. https://doi.org/10.1111/ jphs.12167.

16. Hovinga CA, Asato MR, Manjunath R, Wheless JW, Phelps SJ, Sheth RD, et al. Association of non-adherence to antiepileptic drugs and seizures, quality of life, and productivity: survey of patients with epilepsy and physicians. Epilepsy Behav. 2008;13(2):316-22. https://doi.org/10.1016/j.yebeh.2008.03. 009 Pubmed:18472303.

17. Faught E, Duh MS, Weiner JR, Guérin A, Cunnington MC. Nonadherence to antiepileptic drugs and increased mortality: findings from the RANSOM study. Neurology. 2008;71(20):1572-8. https://doi.org/10.1212/01.wnl. 0000319693.10338.b9 Pubmed:18565827.

18. Razali SM, Yassin AM. Complementary treatment of psychotic and epileptic patients in Malaysia. Transcult Psychiatry. 2008;45(3):455-69. https://doi.org/ 10.1177/1363461508094676 Pubmed:18799643.

19. Malaysia Healthcare. The healthcare system in Malaysia. 2020. https://www. mhtc.org.my/mhtc/2020/02/02/the-healthcare-system-in-malaysia/. Accessed Jan 032021.

20. Tahir NM, Thomas P, Bakry MM, Ali A, Li SC. Cost-effectiveness of newer antiepileptic drugs (Aeds) for Management of Partial Epilepsy in children in Malaysia. Value Health. 2016;19(7):A875.

21. Red Cover. AIA 39 Critical IInesses Insurance Plans Malaysia. Kuala Lumpur: AIA Insurance Malaysia;

22. Sharma E, Dubey AK, Malhotra S, Manocha S, Handu S. Use of complementary and alternative medicines in Indian elderly patients. Natl J Physiol Pharm Pharmacol. 2017;7(9):929. https://doi.org/10.5455/njppp.2017. 7.0411401052017.

23. Sirven Jl, Drazkowski JF, Zimmerman RS, Bortz JJ, Shulman DL, Macleish M. Complementary/alternative medicine for epilepsy in Arizona. Neurology. 2003;61(4):576-7. https://doi.org/10.1212/01.wnl.0000073541.08356.47 Pubmed:12939447.

24. Liow K, Ablah E, Nguyen JC, Sadler T, Wolfe D, Tran KD, et al. Pattern and frequency of use of complementary and alternative medicine among patients with epilepsy in the midwestern United States. Epilepsy Behav. 2007;10(4):576-82. https://doi.org/10.1016/j.yebeh.2007.02.017 Pubmed: 17459780 .

25. McConnell BV, Applegate M, Keniston A, Kluger B, Maa EH. Use of complementary and alternative medicine in an urban county hospital epilepsy clinic. Epilepsy Behav. 2014;34:73-6. https://doi.org/10.1016/j.yebeh. 2014.03.011 Pubmed:24726950.

26. Al Asmi A, Al Maniri A, Al-Farsi YM, Burke DT, Al Asfoor FM, Al Busaidi I, et al. Types and sociodemographic correlates of complementary and alternative medicine (CAM) use among people with epilepsy in Oman. Epilepsy Behav. 2013;29(2):361-6. https://doi.org/10.1016/j.yebeh.2013.07.022 Pubmed: 24011398.

27. Bhalerao MS, Bolshete PM, Swar BD, Bangera TA, Kolhe VR, Tambe MJ, et al. Use of and satisfaction with complementary and alternative medicine in four chronic diseases: a cross-sectional study from India. Natl Med J India. 2013;26(2):75-8 Pubmed:24093979

28. Tandon M, Prabhakar S, Pandhi P. Pattern of use of complementary/ alternative medicine (CAM) in epileptic patients in a tertiary care hospital in India. Pharmacoepidemiol Drug Saf. 2002;11(6):457-63. https://doi.org/10. 1002/pds.731 Pubmed:12426930.

29. Naveen GH, Sinha S, Girish N, Taly AB, Varambally S, Gangadhar BN. Yoga and epilepsy: what do patients perceive? Indian J Psychiatry. 2013;55(Suppl 3):S390-3. https://doi.org/10.4103/0019-5545.116306 Pubmed:24049205.

30. Kuan YC, Yen DJ, Yiu CH, Lin YY, Kwan SY, Chen C, et al. Treatment-seeking behavior of people with epilepsy in Taiwan: a preliminary study. Epilepsy Behav. 2011;22(2):308-12. https://doi.org/10.1016/j.yebeh.2011.06.034 Pubmed:21813332.

31. Islahudin F, Shahdan IA, Mohamad-Samuri S. Association between belief and attitude toward preference of complementary alternative medicine use. Patient Prefer Adherence. 2017;11:913-8. https://doi.org/10.2147/PPA. S132282 Pubmed:28546742.

32. Koh HL, Teo HH, Ng HL. Pharmacists' patterns of use, knowledge, and attitudes toward complementary and alternative medicine. J Altern Complement Med. 2003;9(1):51-63. https://doi.org/10.1089/ 107628003321536940 Pubmed:12676035.

33. Yeong S, Choong Y. Knowledge and characteristics of herbal supplement usage among community pharmacy customers in a Malaysian population. Complement Ther Med. 2017;35:92-108. 
34. Warriner S, Bryan K, Brown AM. Women's attitude towards the use of complementary and alternative medicines (CAM) in pregnancy. Midwifery. 2014;30(1):138-43. https://doi.org/10.1016/j.midw.2013.03.004 Pubmed: 23631887.

35. Xue CC, Zhang AL, Lin V, Da Costa C, Story DF. Complementary and alternative medicine use in Australia: a national population-based survey. J Altern Complement Med. 2007;13(6):643-50. https://doi.org/10.1089/acm. 2006.6355 Pubmed:17718647.

36. Shi L, Liu J, Koleva Y, Fonseca V, Kalsekar A, Pawaskar M. Concordance of adherence measurement using self-reported adherence questionnaires and medication monitoring devices. Pharmacoeconomics. 2010;28(12):1097-107. https://doi.org/10.2165/11537400-000000000-00000 Pubmed:21080735.

37. Wu JR, Lennie TA, Chung ML, Frazier SK, Dekker RL, Biddle MJ, Moser DK. Medication adherence mediates the relationship between marital status and cardiac event-free survival in patients with heart failure. Heart Lung. 2012;41(2):107-14. https://doi.org/10.1016/j.hrtlng.2011.09.009 Pubmed: 22054720 .

38. Ferrari CMM, de Sousa RMC, Castro LH. Factors associated with treatment non-adherence in patients with epilepsy in Brazil. Seizure. 2013;22(5):384-9. https://doi.org/10.1016/.jseizure.2013.02.006 Pubmed:23478508.

39. Zeber JE, Copeland LA, Pugh MJV. Variation in antiepileptic drug adherence among older patients with new-onset epilepsy. Ann Pharmacother. 2010; 44(12):1896-904. https://doi.org/10.1345/aph.1P385 Pubmed:21045168.

40. Sweileh WM, Ihbesheh MS, Jarar IS, Taha ASA, Sawalha AF, Zyoud SH, et al. Self-reported medication adherence and treatment satisfaction in patients with epilepsy. Epilepsy Behav. 2011;21(3):301-5. https://doi.org/10.1016/j. yebeh.2011.04.011 Pubmed:21576040.

41. Bosak M, Słowik A. Use of complementary and alternative medicine among adults with epilepsy in a university epilepsy clinic in Poland. Epilepsy Behav. 2019;98:40-4.

\section{Publisher's Note}

Springer Nature remains neutral with regard to jurisdictional claims in published maps and institutional affiliations.

Ready to submit your research? Choose BMC and benefit from:

- fast, convenient online submission

- thorough peer review by experienced researchers in your field

- rapid publication on acceptance

- support for research data, including large and complex data types

- gold Open Access which fosters wider collaboration and increased citations

- maximum visibility for your research: over $100 \mathrm{M}$ website views per year

At $\mathrm{BMC}$, research is always in progress.

Learn more biomedcentral.com/submissions 